OPEN ACCESS

Edited by:

Edward S. Ruthazer, McGill University, Canada

Reviewed by:

Arseny S. Khakhalin,

Bard College, United States

Hernan Lopez-Schier, Helmholtz Center Munich-German Research Center for Environmental Health, Germany

${ }^{*}$ Correspondence: Thomas Preuss tpreuss@hunter.cuny.edu

Received: 26 October 2018 Accepted: 24 January 2019 Published: 18 February 2019

Citation:

Mclntyre $C$ and Preuss $T$ (2019) Influence of Stimulus Intensity on Multimodal Integration in the

Startle Escape System of Goldfish.

Front. Neural Circuits 13:7. doi: 10.3389/fncir.2019.00007

\section{Influence of Stimulus Intensity on Multimodal Integration in the Startle Escape System of Goldfish}

\author{
Camille McIntyre and Thomas Preuss* \\ Department of Psychology, Hunter College, City University of New York, New York, NY, United States
}

Processing of multimodal information is essential for an organism to respond to environmental events. However, how multimodal integration in neurons translates into behavior is far from clear. Here, we investigate integration of biologically relevant visual and auditory information in the goldfish startle escape system in which paired Mauthnercells (M-cells) initiate the behavior. Sound pips and visual looms as well as multimodal combinations of these stimuli were tested for their effectiveness of evoking the startle response. Results showed that adding a low intensity sound early during a visual loom (low visual effectiveness) produced a supralinear increase in startle responsiveness as compared to an increase expected from a linear summation of the two unimodal stimuli. In contrast, adding a sound pip late during the loom (high visual effectiveness) increased responsiveness consistent with a linear multimodal integration of the two stimuli. Together the results confirm the Inverse Effectiveness Principle (IEP) of multimodal integration proposed in other species. Given the well-established role of the M-cell as a multimodal integrator, these results suggest that IEP is computed in individual neurons that initiate vital behavioral decisions.

\begin{abstract}
Keywords: multimodal integration, behavioral decision-making, visual loom, inverse effectiveness principle, Mauthner-cell, startle plasticity
\end{abstract}

\section{INTRODUCTION}

Integration of sensory information from different modalities is essential for decision-making of appropriately timed behavioral responses. In vertebrates, neurons processing multimodal inputs are found throughout the CNS, prominently the cortical sensory processing areas and superior colliculus in mammals (Meredith et al., 1987; Wallace et al., 1998; Ghazanfar and Schroeder, 2006; King and Walker, 2012), and the optic tectum and hindbrain in birds, amphibians, and fish (Winkowski and Knudsen, 2006; Hiramoto and Cline, 2009; Mu et al., 2012; Medan et al., 2018). Multimodal integration depends on overlapping timing and/or spatial location of unimodal stimuli and typically results in an enhancement of the neural and behavioral response. Specifically, the Inverse Effectiveness Principle (IEP) predicts an inverse relationship between individual effectiveness of two unimodal stimuli presented alone and their combined effectiveness, i.e., multimodal integration of two weak stimuli will produce a response that is disproportionately larger than the response evoked by the integration of two strong stimuli. (Meredith and Stein, 1986; Stein et al., 2014). However, establishing causal links between the firing patterns in multimodal neurons and behavioral supporting the IEP has proven difficult (Stanford and Stein, 2007; Holmes, 2009; van Atteveldt et al., 2014). Thus, our goal was to study the IEP phenomenon in a downstream circuit where a distinct behavior can be directly related to sensorimotor neural processing. 
We used the startle escape behavior in goldfish, which is controlled by a pair of high-threshold, integrate-and-fire neurons, the Mauthner-cells (M-cells). M-cells receive visual and acoustico-lateralis inputs via separate dendrites, and a single action potential (AP) in one M-cell activates contralateral spinal motor circuits for a C-shaped body bend, or "C-start" startle escape response away from a potential threat (Fetcho, 1991; Eaton et al., 2001; Weiss et al., 2006). Importantly, the oneto-one relationship between $\mathrm{M}$-cell threshold and behavioral threshold casually links sensory integration at the M-cell level to startle behavior (Zottoli, 1977; Weiss et al., 2006). Indeed, auditory 8th nerve afferences provide disynaptic $(1.8 \mathrm{~ms})$ input via mixed electrical and chemical synapses to the lateral M-cell dendrite (Zottoli, 1977; Szabo et al., 2006). Visual information is mediated through a polysynaptic pathway $(\sim 20 \mathrm{~ms})$ to the ventral dendrite via the optic tectum (Zottoli et al., 1987; Preuss et al., 2006; Dunn et al., 2016). Similarly, abrupt (5 ms) sound pips or gradually increasing (300-1,000 ms) visual looms evoke startles initiated by M-cells (Preuss and Faber, 2003; Preuss et al., 2006; Weiss et al., 2006; Burgess and Granato, 2007; Dunn et al., 2016). Here, we explore the multimodal integration of these two stimuli in goldfish and results indicate supralinear and linear summation of startle rates consistent with the IEP.

\section{MATERIALS AND METHODS}

\section{Subjects}

Twelve goldfish (Carassius auratus) purchased from Billy Bland Fishery (Taylor, AR) of standard body length (mean: $6.15 \pm 0.39 \mathrm{~cm}$ ) and weight (mean: $9.17 \pm 1.53 \mathrm{~g}$ ) maintained in holding tanks $\left(95 \mathrm{~L} ; 30 \times 30 \times 60 \mathrm{~cm}\right.$; pH 7.2-7.6, $18 \pm 1^{\circ} \mathrm{C}$ ) were acclimated for at least 1 week prior to experimentation.

\section{Apparatus and Stimuli}

Experiments were performed in a circular tank $(77.5 \mathrm{~cm}$ diameter, $30.5 \mathrm{~cm}$ deep) located on an anti-vibration table to minimize external mechanosensory cues and covered with a translucent plastic lid, which served as a projection screen for visual stimuli (Preuss et al., 2006). A circular mesh (27.6 $\mathrm{cm}$ height; $39 \mathrm{~cm}$ diameter) confined the swimming arena. Startle escape behavior was recorded at 1,000 frames/s (Olympus iSpeed2; Figure 1A). Visual loom stimuli consisted of a projected black disc exponentially expanding in size (initial size $8 \mathrm{~mm}$, final size $360 \mathrm{~mm}$, duration $900 \mathrm{~ms}$ ) produced with custom software (Visloom 1.01) and projected onto the lid with a DLP projector (Plus U4-131; display rate $60 \mathrm{H}$; Figure 1A). The vertical position of goldfish in the water column varied between 4 and $18 \mathrm{~cm}$ resulting in initial view angles subtended on the retina between 2.5 and 11.4 degree (view angle $\theta=2^{*} \tan ^{-1}(\mathrm{~d} / 2 \mathrm{~s}$ ), where $\mathrm{d}$ is the diameter of the projected disk and $s$ the distance from the screen to the fish; Figure 1A). The luminance ratio $\left(\mathrm{L}_{\text {High }} / \mathrm{L}_{\text {Low }}\right)$ between background screen (55 lux) and the expanding disc (19 lux) was 1.8.

Auditory stimuli consisted of sound pips $(200 \mathrm{~Hz} ; 5 \mathrm{~ms}$; 152 or $158 \mathrm{~dB}$ re $1 \mu \mathrm{Pa}$ in water), generated by a stimulator
(Master8 AMP), a function generator (Agilent 33210), a power amplifier (Samson Servo 120), and were delivered via either of two underwater loudspeakers (Electro-Voice Model UW-30).

\section{Stimulus Design and Specific Experiments}

In goldfish, sound pips produce a sigmoid stimulus response curve (Neumeister et al., 2008), whereas startle rates during a visual loom increase exponentially, i.e., few responses early and peak response rates at 70\%-90\% of loom duration (Preuss et al., 2006). Accordingly, to produce multimodal stimuli with varying effectiveness, we applied low effective sound pips at different times during a visual loom. However, true stimulus effectiveness can only be assessed after data analysis and revealed that experiment 1 did not include a highly effective stimulus combination. Thus, we performed a follow-up experiment (Exp. 2) in a new set of fish where multimodal stimulus effectiveness was increased by triggering sound stimuli later in the loom and using a higher intensity sound. Stimulus presentation was randomized for every fish.

Experiment 1 was run on six fish, each subjected to four different paradigms, with six presentations for every stimulus namely, audio only (152 dB), visual only, as well as a combination of the two where the audio stimulus was triggered either at 221 or $672 \mathrm{~ms}$ after loom onset referred to as $A V_{\text {Low }}$ and $\mathrm{AV}_{\mathrm{Med}}$, respectively.

Experiment 2 (six fish; five stimulus paradigms; six trials each paradigm) included the auditory and visual stimuli of Exp. 1, an added auditory stimulus of higher intensity ( $158 \mathrm{~dB}$ re $1 \mu \mathrm{Pa}$ in water), and two multimodal paradigms where the two auditory stimuli were triggered $832 \mathrm{~ms}$ after loom onset $\left(\mathrm{AV}_{\mathrm{High}} 152 \mathrm{~dB}\right.$ and $\mathrm{AV}_{\text {High }} 158 \mathrm{~dB}$ ).

All procedures were performed according to and approved by the Institutional Animal Care and Use Committee (IACUC) of Hunter College ${ }^{1}$.

\section{Analysis}

The predicted linear multimodal summation of startle probability was calculated based on probability observed in visual only and auditory only stimulus trials using the Addition Rule of Probabilities of independent events $\mathrm{P}(\mathrm{X}$ OR Y $)=\mathrm{P}(\mathrm{X})$ $+\mathrm{P}(\mathrm{Y})-\mathrm{P}(\mathrm{X})^{*} \mathrm{P}(\mathrm{Y})$ (Samuels et al., 2012). Mean \pm standard deviations (SD) are reported in the text.

\section{RESULTS}

Auditory stimuli evoked overall low response probabilities (Exp. 1, $152 \mathrm{~dB}, M=0.14 \pm 0.26$ and Exp. 2, $152 \mathrm{~dB}$ $M=0.06 \pm 0.09 ; 159 \mathrm{~dB} M=0.08 \pm 0.09$; Figure 1B). No significant differences were found between Exp. 1 and 2 for the $152 \mathrm{~dB}$ stimulus $(N=6 ; p=0.85$ Wilcoxon rank-sum test; Cohen's $d=0.46$ ), or between the $152 \mathrm{~dB}$ and $158 \mathrm{~dB}$ auditory stimuli in Exp. $2(N=6 ; p=0.68$; Friedman repeated measure; Cohen's $d=0.35$ ). Essentially, all auditory stimuli showed low effectiveness. In contrast, visual looms elicited sizable mean

\footnotetext{
$\overline{{ }^{1} \text { http://research.hunter.cuny.edu/IACUC.htm }}$
} 
A

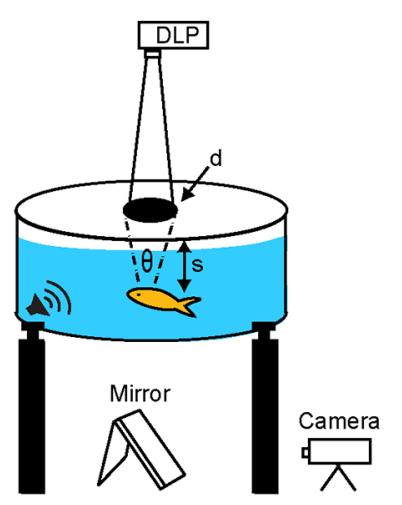

C

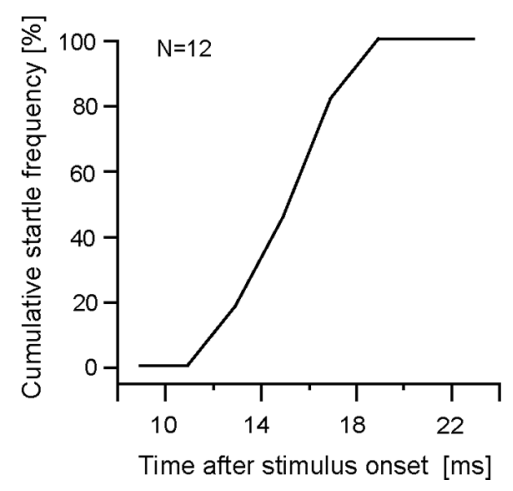

B
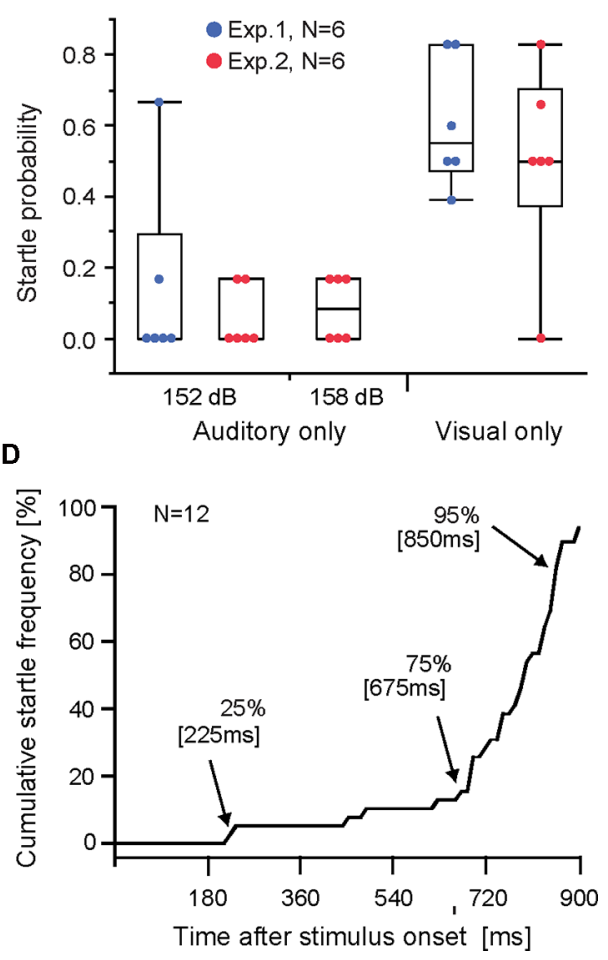

FIGURE 1 | Auditory and visual evoked Mauthner-cell (M-cell) startle responses. (A) Schematic of behavioral setup. Visual loom stimuli were projected onto the translucent lid of the experimental tank and sound pips were delivered through underwater loudspeakers ( $\theta$ indicates subtended view angle, $d$ is the diameter of the projected disk, and $\mathrm{s}$ is the distance from the lid to the fish). (B) Boxplots of startle probabilities to unimodal auditory and visual stimuli used in Exp 1 and 2. Dots indicate data of individual fish. (C) Line graph plotting sound evoked cumulative startle frequency vs. response latency for all audio stimuli trials (152 dB and $158 \mathrm{~dB}$ re $1 \mu \mathrm{Pa}$ in water). (D) Line graph plotting visual evoked cumulative startle frequency vs. response latency. Arrows indicate time points when audio stimuli were triggered in multimodal paradigms. Note: startle escape probabilities increase dynamically during the loom, with most responses occurring between $80 \%$ and $95 \%$ loom duration.

startle probabilities (Exp. 1, $M=0.608 \pm 0.18$ and Exp. 2, $M=0.49 \pm 0.27)$ with no significant difference between Exp. 1 and $2(N=6 ; p=0.78$, Wilcoxon rank-sum test; Cohen's $d=0.47$; Figure 1B).

To illustrate the range of response latencies evoked by auditory stimuli and visual stimuli we combined all responses for a given modality showing that auditory evoked startles occur within a narrow range of latencies (Figure 1C). In contrast, startles in response to visual looms show a wider latency range with most responses occurring between $75 \%-95 \%$ of loom duration (Figure 1D).

We next analyzed startle rates for the different multimodal stimulus paradigms (i.e., $A V_{\text {Low }}, \mathrm{AV}_{\text {Med }}$ and $A V_{\text {High }}$ ) by graphing the frequency of responses over the duration of the loom (Figure 2A). Results show three response modes (Figure 2A: M1, M2, M3) within a time window typical for auditory responses (Figure $\mathbf{2 A}$ dotted lines and $\mathbf{1 C}$ ) suggesting that they are due to a multimodal integration process that enhances responsiveness.

IEP predicts that multimodal integration disproportionately enhances responsiveness more for weaker than for stronger unimodal stimuli combinations (Meredith and Stein, 1986; Holmes, 2009). Accordingly, we compared the observed changes in startle probabilities in multimodal stimulus paradigms with those predicted by a linear summation of the unimodal auditory and visual startle probabilities (see "Materials and Methods" section for details). Visual only startle probabilities for the multimodal response modes (Figure 2A; M1, M2, M3) were derived from those occurring within $30 \mathrm{~ms}$ of a prospective auditory stimulus (arrows Figure 1D).

Results showed higher than predicted startle probabilities for individual fish for the $\mathrm{AV}_{\mathrm{Med}}$ paradigm (Figure 2Bii; $M_{\text {pred }}=0.19 \pm 0.25$ vs. $M_{\text {obser }}=0.53 \pm 0.32$, Cohen's $d=1.18$ ). In contrast, responsiveness for the $\mathrm{AV}_{\text {Low }}$ paradigm $\left(\mathrm{M}_{\text {pred }}=0.16 \pm 0.25\right.$ vs. $\mathrm{M}_{\text {obser }}=0.33 \pm 0.29$; Cohen's $d=0.63)$ and the two $\mathrm{AV}_{\mathrm{High}}$ paradigms $\left(152 \mathrm{~dB}: \mathrm{M}_{\text {pred }}=0.21 \pm 0.15\right.$ vs. $\mathrm{M}_{\text {obser }}=0.22 \pm 0.17$, Cohen's $d=0.06 ; 158 \mathrm{~dB}: \mathrm{M}_{\text {pred }}=0.19 \pm 0.12$ vs. $\mathrm{M}_{\text {obser }}=0.28 \pm 0.14$ Cohen's $\left.d=0.69\right)$ was variable or even less than predicted for some fish (Figures 2Bi,iii,iv). Comparing the evoked changes for a given AV stimulus 


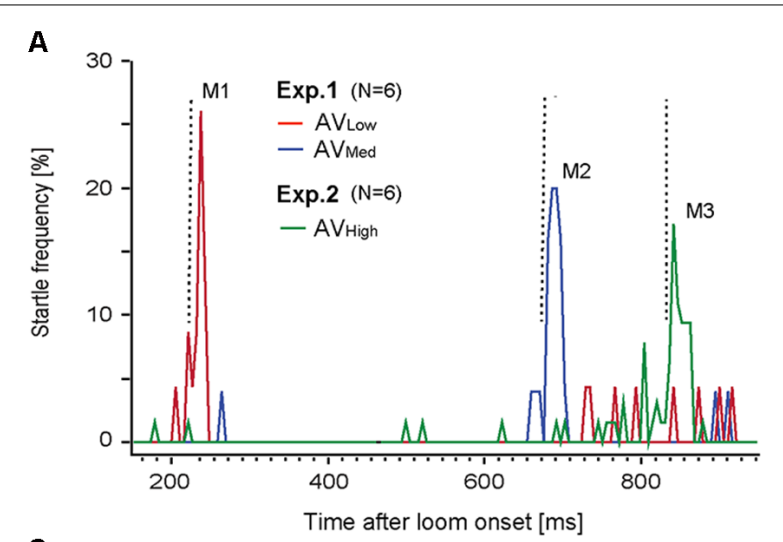

B
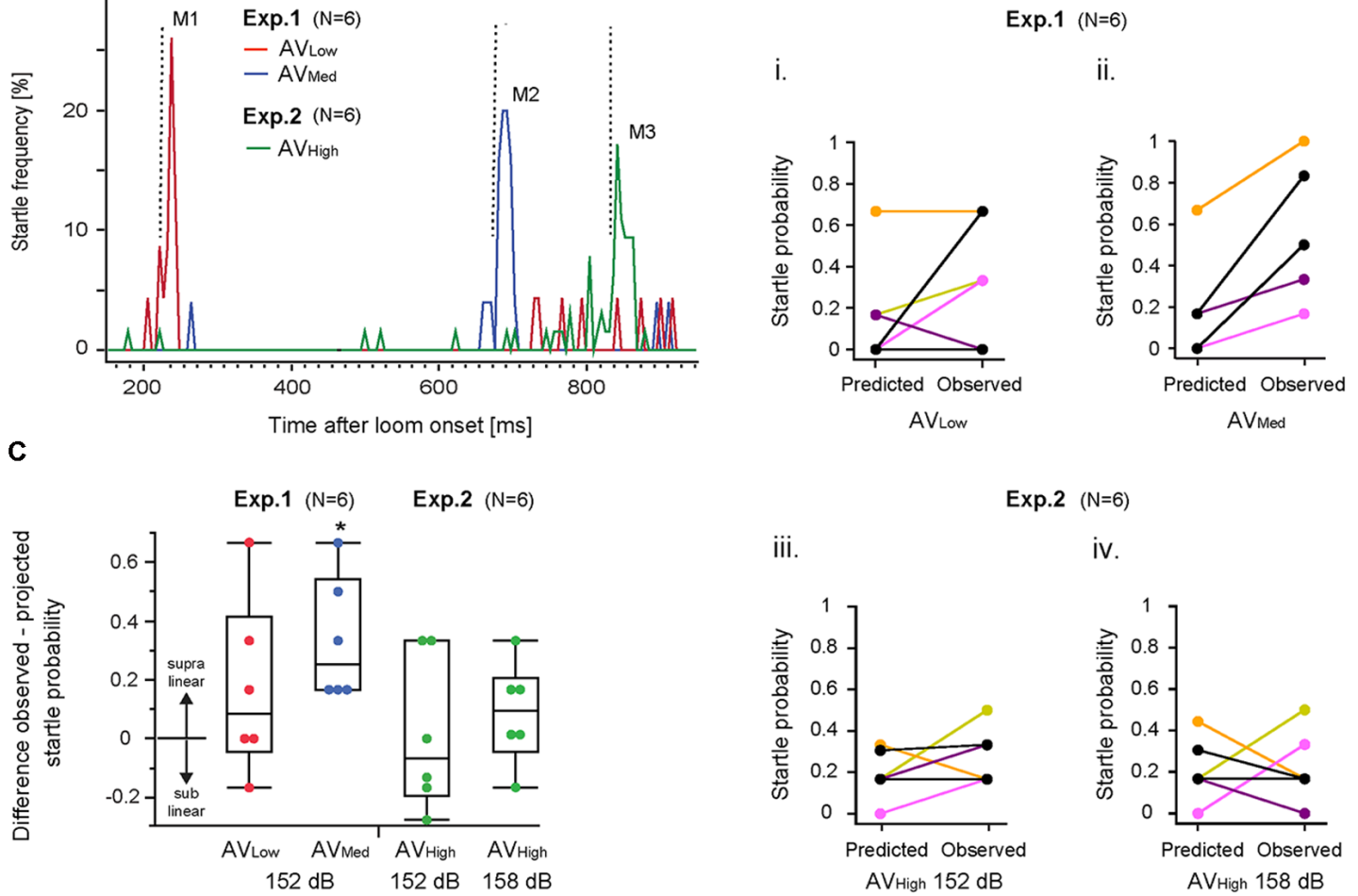

FIGURE 2 | Multimodal integration in the M-cell startle system. (A) Line graph illustrates startle frequency plotted against visual loom duration for all three audio-visual (AV) stimulus paradigms. M1, M2, M3 represent distinct frequency modes for $A V_{\text {Low }}$ and $A V_{\text {Med }}$ or $A V_{\text {High }}$ trials, respectively. Vertical dotted lines indicate onset of the auditory stimulus. (B) Graph illustrates observed and predicted individual startle escape probability for $A V_{\text {Low }}$ and $A V_{\text {Med }}$ stimulus paradigms using an auditory stimulus of $152 \mathrm{~dB}$ re $1 \mu \mathrm{Pa}$ in water (i,ii) and the $A V_{\text {High }}$ paradigms involving auditory stimuli of $152 \mathrm{~dB}$ re $1 \mu \mathrm{Pa}$ in water (iii) and $158 \mathrm{~dB}$ re $1 \mu \mathrm{Pa}$ in water (iv). Predicted startle escape probabilities were based on linear summation of response probabilities evoked in unimodal visual only and auditory only stimulus trials. Note: fish overlap in (Bii). (C) Box plots of differences between observed minus predicted startle escape response probabilities for the indicated AV stimulus paradigm $\left({ }^{*} p=0.043\right.$, one-sample $t$-test with a test value of 0 , i.e., linear summation; $\left.N=6\right)$.

paradigm to a hypothetical value of zero (i.e., to a linear summation; two-tailed, single sample $t$-test) revealed a supralinear increase in startle probability for the $A V_{\text {Med }}$ paradigm (Figure 2C; $p=0.0118$; $p=0.04$ after BenjaminiHochberg correction). No significant differences to a linear summation of startle probabilities was found for $\mathrm{AV}_{\text {low }}$ $(p=0.23), A V_{\text {high }} 152 \mathrm{~dB}(p=0.90)$, and $\mathrm{AV}_{\text {high }} 158 \mathrm{~dB}$ $(p=27$; Figure 2C).

\section{DISCUSSION}

Here, we asked if the IEP (Meredith and Stein, 1986) applies for downstream sensorimotor neurons that directly initiate behavior such as the M-cells. Our findings largely support this notion. Specifically, we observed startle rates consistent with a linear integration of highly effective stimuli, but a supralinear multimodal integration to stimuli of reduced effectiveness $\left(A V_{\text {med }}\right)$, i.e., an inverse relationship between the individual effectiveness of two stimuli and their combined effectiveness. However, the $A V_{\text {low }}$ paradigm did not produce the largest enhancement. Such a discrepancy to IEP might be due to stimulus floor effects
(Holmes, 2009), and has been previously observed in for multimodal integration in the auditory cortex of primates (Lakatos et al., 2007).

Is the $\mathrm{M}$-cell indeed the site of multimodal integration? Indeed, M-cell recordings in African cichlid fish and zebrafish revealed that a preceding light flash enhances auditory evoked synaptic currents, startle responsiveness, and directionality (Page and Sutterlin, 1970; Canfield, 2003, 2006; Mu et al., 2012). Importantly, chronic recordings in free-swimming goldfish and imaging in zebrafish showed visual loom stimuli and acoustic stimuli both trigger M-cell APs and initiate startle (Zottoli, 1977; Preuss et al., 2006; Weiss et al., 2006; Dunn et al., 2016). The presumed role of the M-cell is to initiate early parts of startle directly and/or to control threshold in segmental M-cell homologs, which are part of the brainstem escape network that produces later stages of the startle escape behavior (Liu and Fetcho, 1999; Gahtan et al., 2002; Kohashi and Oda, 2008; Nakayama and Oda, 2014; Neki et al., 2014). In other words, the $\mathrm{M}$-cell is the first reticulospinal neuron active during a startle escape, or C-start, and the final common path for startle decisions (Zottoli, 1977; Fetcho, 1991; Weiss et al., 2006). 
$\mathrm{M}$-cell in vivo recordings showed that back propagating visual and auditory postsynaptic synaptic potentials (PSPs) interact at the dendritic level (Medan et al., 2018). Also, M-cell dendrites possess membrane non-linearities that enhance the effectiveness of such PSPs (Faber and Korn, 1986; Medan and Preuss, 2014). Both these properties likely contribute to the multimodal integration observed here. The latter notion however, does not exclude multimodal tectal neurons providing also critical input to the M-cell (Hiramoto and Cline, 2009; Truszkowski et al., 2017). Moreover, startle (i.e., M-cell) threshold is tightly controlled by at least two independent feedforward inhibition systems, which further influence sensory processing and multimodal integration (Preuss et al., 2006; Medan and Preuss, 2014; Medan et al., 2018). Together these findings suggest that a single neuron such as the $\mathrm{M}$-cell can provide a neural correlate for the IEP phenomenon. In mammals, evidence for IEP in individual neurons derives from, e.g., recordings in cerebellar granule cells and superior colliculus neurons showing supralinear summation in spike rates during simultaneous auditory and visual stimulation (Ishikawa et al., 2015; Miller et al., 2015).

We used a stimulus combination that conceptually mimicked a diving bird breaking the water surface (Medan and Preuss, 2014). Thus, it is not surprising that all multimodal stimulus combinations enhanced startle escape responsiveness when compared to unimodal stimulus conditions. Functionally, such an enhancement might be particularly important when the salience of the individual stimuli is still low vs. a situation where

\section{REFERENCES}

Burgess, H. A., and Granato, M. (2007). Sensorimotor gating in larval zebrafish. J. Neurosci. 27, 4984-4994. doi: 10.1523/JNEUROSCI.0615-07.2007

Canfield, J. G. (2003). Temporal constraints on visually directed C-start responses: behavioral and physiological correlates. Brain Behav. Evol. 61, 148-158. doi: $10.1159 / 000069751$

Canfield, J. G. (2006). Functional evidence for visuospatial coding in the Mauthner neuron. Brain Behav. Evol. 67, 188-202. doi: 10.1159/000091652

Dunn, T. W., Gebhardt, C., Naumann, E. A., Riegler, C., Ahrens, M. B., Engert, F., et al. (2016). Neural circuits underlying visually evoked escapes in larval zebrafish. Neuron 89, 613-628. doi: 10.1016/j.neuron.2015.12.021

Eaton, R. C., Lee, R. K. K., and Foreman, M. B. (2001). The Mauthner cell and other identified neurons of the brainstem escape network of fish. Prog. Neurobiol. 63, 467-485. doi: 10.1016/s0301-0082(00)00047-2

Faber, D. S., and Korn, H. (1986). Instantaneous inward rectification in the Mauthner cell: a postsynaptic booster for excitatory inputs. Neuroscience 19, 1037-1043. doi: 10.1016/0306-4522(86)90120-x

Fetcho, J. R. (1991). Spinal network of the Mauthner cell (Part 2 of 2). Brain Behav. Evol. 37, 307-316. doi: 10.1159/000316094

Gahtan, E., Sankrithi, N., Campos, J. B., and O’Malley, D. M. (2002). Evidence for a widespread brain stem escape network in larval zebrafish. J. Neurophysiol. 87, 608-614. doi: 10.1152/jn.00596.2001

Ghazanfar, A. A., and Schroeder, C. E. (2006). Is neocortex essentially multisensory? Trends Cogn. Sci. 10, 278-285. doi: 10.1016/j.tics.2006. 04.008

Hiramoto, M., and Cline, H. T. (2009). Convergence of multisensory inputs in Xenopus tadpole tectum. Dev. Neurobiol. 69, 959-971. doi: 10.1002/dneu. 20754

Holmes, N. P. (2009). The principle of inverse effectiveness in multisensory integration: some statistical considerations. Brain Topogr. 21, 168-176. doi: 10.1007/s10548-009-0097-2 stimuli are already highly salient (Holmes and Spence, 2005; ten Oever et al., 2016).

\section{DATA AVAILABILITY}

All datasets generated for this study are included in the manuscript.

\section{AUTHOR CONTRIBUTIONS}

CM collected and analyzed data and wrote the manuscript. TP designed the study and revised the manuscript.

\section{FUNDING}

This work was supported by the NSF IOS 1147172 and the City University of New York CUNY MBRS-RISE (IM) program.

\section{ACKNOWLEDGMENTS}

We thank Toni Tobias for help with experiments and Dr. Martin Chodorow for help with statistical analysis. We also thank Dr. Heike Neumeister, Dr. Jim Gordon, and Dr. Daniel Bronson for comments on text and figures, as well as past and present members of the Preuss Lab for advice and support. The results were part of a Masters Thesis of CM at Hunter College of CUNY School of Arts and Sciences, Theses 2016.

Holmes, N. P., and Spence, C. (2005). Multisensory integration: space, time and superadditivity. Curr. Biol. 15, R762-R764. doi: 10.1016/j.cub.2005.08.058

Ishikawa, T., Shimuta, M., and Häusser, M. (2015). Multimodal sensory integration in single cerebellar granule cells in vivo. Elife 4:e12916. doi: 10.7554/eLife.12916

King, A. J., and Walker, K. M. (2012). Integrating information from different senses in the auditory cortex. Biol. Cybern. 106, 617-625. doi: 10.1007/s00422012-0502-x

Kohashi, T., and Oda, Y. (2008). Initiation of Mauthner- or non-Mauthnermediated fast escape evoked by different modes of sensory input. J. Neurosci. 28, 10641-10653. doi: 10.1523/JNEUROSCI.1435-08.2008

Lakatos, P., Chen, C. M., O'Connell, M. N., Mills, A., and Schroeder, C. E. (2007). Neuronal oscillations and multisensory interaction in primary auditory cortex. Neuron 53, 279-292. doi: 10.1016/j.neuron.2006.12.011

Liu, K. S., and Fetcho, J. R. (1999). Laser ablations reveal functional relationships of segmental hindbrain neurons in zebrafish. Neuron 23, 325-335. doi: 10.1016/s0896-6273(00)80783-7

Medan, V., Mäki-Marttunen, T., Sztarker, J., and Preuss, T. (2018). Differential processing in modality-specific Mauthner cell dendrites. J. Physiol. 596, 667-689. doi: 10.1113/JP274861

Medan, V., and Preuss, T. (2014). The Mauthner-cell circuit of fish as a model system for startle plasticity. J. Physiol. Paris 108, 129-140. doi: 10.1016/j.jphysparis.2014.07.006

Meredith, M. A., Nemitz, J. W., and Stein, B. E. (1987). Determinants of multisensory integration in superior colliculus neurons. J. Neurosci. 7, 3215-3229. doi: 10.1523/jneurosci.07-10-03215.1987

Meredith, M. A., and Stein, B. E. (1986). Visual, auditory and somatosensory convergence on cells in superior colliculus results in multisensory integration. J. Neurophysiol. 56, 640-662. doi: 10.1152/jn.1986.56.3.640

Miller, R. L., Pluta, S. R., Stein, B. E., and Rowland, B. A. (2015). Relative unisensory strength and timing predict their multisensory product. J. Neurosci. 35, 5213-5220. doi: 10.1523/JNEUROSCI.4771-14.2015 
Mu, Y., Li, X. Q., Zhang, B., and Du, J. L. (2012). Visual input modulates audiomotor function via hypothalamic dopaminergic neurons through a cooperative mechanism. Neuron 75, 688-699. doi: 10.1016/j.neuron.2012. 05.035

Nakayama, H., and Oda, Y. (2014). Common sensory inputs and differential excitability of segmentally homologous reticulospinal neurons in the hindbrain. J. Neurosci. 24, 3199-3209. doi: 10.1523/JNEUROSCI.4419-03.2004

Neki, D., Nakayama, H., Fujii, T., Matsui-Furusho, H., and Oda, Y. (2014). Functional motifs composed of morphologically homologous neurons repeated in the hindbrain segments. J. Neurosci. 34, 3291-3302. doi: 10.1523/JNEUROSCI.4610-13.2014

Neumeister, H., Szabo, T. M., and Preuss, T. (2008). Behavioral and physiological characterization of sensorimotor-gating in the goldfish startle response. J. Neurophysiol. 99, 1493-1502. doi: 10.1152/jn.00959.2007

Page, C. H., and Sutterlin, A. M. (1970). Visual-auditory unit responses in the goldfish tegmentum. J. Neurophysiol. 33, 129-136. doi: 10.1152/jn.1970. 33.1.129

Preuss, T., and Faber, D. S. (2003). Central cellular mechanisms underlying temperature-dependent changes in the goldfish startle-escape behavior. J. Neurosci. 23, 5617-5626. doi: 10.1523/jneurosci.23-13-05617.2003

Preuss, T., Osei-Bonsu, P. E., Weiss, S. A., Wang, C., and Faber, D. S. (2006). Neural representation of object approach in a decision-making motor circuit. J. Neurosci. 26, 3454-3464. doi: 10.1523/JNEUROSCI.5259-05.2006

Samuels, M. L., Witmer, J. A., and Schaffner, A. A. (2012). Statistics for the Life Sciences. 4th Edn. Upper Saddle River, NJ: Pearson/Prentice Hall.

Stanford, T. R., and Stein, B. E. (2007). Superadditivity in multisensory integration: putting the computation in context. Neuroreport 18, 787-792. doi: 10.1097/WNR.0b013e3280c1e315

Stein, B. E., Stanford, T. R., and Rowland, B. A. (2014). Development of multisensory integration from the perspective of the individual neuron. Nat. Rev. Neurosci. 15, 520-535. doi: 10.1038/nrn3742

Szabo, T. M., Weiss, S. A., Faber, D. S., and Preuss, T. (2006). Representation of auditory signals in the M-cell: role of electrical synapses. J. Neurophysiol. 95, 2617-2629. doi: 10.1152/jn.01287.2005

ten Oever, S., Romei, V., Van Atteveldt, N., Soto-Faraco, S., Murray, M. M., and Matusz, P. J. (2016). The COGs (context, object and goals) in multisensory processing. Exp. Brain Res. 234, 1307-1323. doi: 10.1007/s00221-0164590-z

Truszkowski, T. L., Carrillo, O. A., Bleier, J., Ramirez-Vizcarrondo, C. M., Felch, D. L., McQuillan, M., et al. (2017). A cellular mechanism for inverse effectiveness in multisensory integration. Elife 6:e25392. doi: 10.7554/eLife. 25392

van Atteveldt, N., Murray, M. M., Thut, G., and Schroeder, C. E. (2014). Multisensory integration: flexible use of general operations. Neuron 81, 1240-1253. doi: 10.1016/j.neuron.2014.02.044

Wallace, M. T., Meredith, M. A., and Stein, B. E. (1998). Multisensory integration in the superior colliculus of the alert cat. J. Neurophysiol. 80, 1006-1010. doi: 10.1152/jn.1998.80.2.1006

Weiss, S. A., Zottoli, S. J., Do, S. C., Faber, D. S., and Preuss, T. (2006). Correlation of C-start behaviors with neural activity recorded from the hindbrain in free-swimming goldfish (Carassius auratus). J. Exp. Biol. 209, 4788-4801. doi: $10.1242 /$ jeb.02582

Winkowski, D. E., and Knudsen, E. I. (2006). Top-down gain control of the auditory space map by gaze control circuitry in the barn owl. Nature 439, 336-339. doi: 10.1038/nature04411

Zottoli, S. J. (1977). Correlation of the startle reflex and Mauthner cell auditory responses in unrestrained goldfish. J. Exp. Biol. 66, 243-254.

Zottoli, S. J., Hordes, A. R., and Faber, D. S. (1987). Localization of optic tectal input to the ventral dendrite of the goldfish Mauthner cell. Brain Res. 401, 113-121. doi: 10.1016/0006-8993(87)91170-x

Conflict of Interest Statement: The authors declare that the research was conducted in the absence of any commercial or financial relationships that could be construed as a potential conflict of interest.

Copyright (c) 2019 McIntyre and Preuss. This is an open-access article distributed under the terms of the Creative Commons Attribution License (CC BY). The use, distribution or reproduction in other forums is permitted, provided the original author(s) and the copyright owner(s) are credited and that the original publication in this journal is cited, in accordance with accepted academic practice. No use, distribution or reproduction is permitted which does not comply with these terms. 